\title{
Mitigating heat stress of dairy cows bred in a free-stall barn by sprinkler systems coupled with forced ventilation
}

\author{
Alessandro D'Emilio, ${ }^{1}$ Simona M.C. Porto, ${ }^{1}$ Giovanni Cascone, ${ }^{1}$ Marco Bella, ${ }^{2}$ Marco Gulino ${ }^{2}$ \\ ${ }^{1}$ Building and Land Engineering Section; ${ }^{2}$ Animal Production Division, Department of Agriculture, Food and \\ Environment, University of Catania, Italy
}

\begin{abstract}
This paper presents the results of a research study which had the objective of investigating the effect of a sprinkler system coupled with forced ventilation on the heat stress of dairy cows bred in a free stall barn without paddock. To this aim, an experiment was carried out inside a free-stall dairy house equipped with two different cooling systems: a fogging system associated with forced ventilation in the resting area and a sprinkler system associated with forced ventilation in the feeding alley. The experiment regarded two adjacent pens of the barn and was constituted by three different trials carried out in the following periods: $27^{\text {th }}$ June - $7^{\text {th }}$ July (P1), 25 th July - $4^{\text {th }}$ August (P2), 24 $4^{\text {th }}$ August $-3^{\text {rd }}$ September (P3). The experimental protocol of each trial required that the treatment group was housed in one pen where the two cooling systems were always activated following an established timetable, whereas the control group was housed in the other pen, where the sprinkler system associated with forced ventilation was always deactivated. Climatic parameters were measured inside
\end{abstract}

Correspondence: Simona M.C. Porto, Building and Land Engineering Section, Department of Agriculture, Food and Environment, University of Catania, via S. Sofia 100, 95123 Catania, Italy. E-mail: siporto@unict.it

Key words: Animal welfare; breeding environment; hot climate; microclimate control.

Acknowledgements: the research activity described in this paper is part of the research project FIR 2014 entitled Development of an automatic monitoring system for the study of the individual dairy cow behaviour in free-housing system funded by the University of Catania (Italy) and coordinated by Ph.D. Eng. Simona M.C. Porto. Furthermore, the authors are grateful to the farm ALPA S.S. for giving the opportunity of carrying out the trial and allowing the installation of the equipment.

Contributions: the authors have contributed equally to the paper.

Ethical standards: the experiment carried out in this study complied with the current Italian laws.

Received for publication: 18 March 2017.

Accepted for publication: 14 June 2017.

CCopyright A. D'Emilio et al., 2017

Licensee PAGEPress, Italy

Journal of Agricultural Engineering 2017; XLVIII:691

doi:10.4081/jae.2017.691

This article is distributed under the terms of the Creative Commons Attribution Noncommercial License (by-nc 4.0) which permits any noncommercial use, distribution, and reproduction in any medium, provided the original author(s) and source are credited. each pen of the barn and outside. Then, thermal humidity index (THI) was calculated. Rectal temperature and respiration rate of a sample of dairy cows were monitored each day during the three periods considered (P1, P2 and P3). During the three trials the cows of both groups were subjected to climatic conditions that resulted in average daily THI values between 72.8 and 74.7 , corresponding to mild or moderate heat stress. However, during daytime, air temperature and relative humidity reached values corresponding to a severe heat stress, as attested by the maximum THI values that were higher than or very close to 80 . Furthermore, it was observed that the sprinklers do not influence the microclimatic conditions. However, the physiological parameters values of the treatment group were always significantly lower than the corresponding ones of the control group. Specifically, the system especially influenced the respiration rate that, in the treatment group, was close to $50 \mathrm{breath} / \mathrm{min}$, while in the control group it reached 70 breath $/ \mathrm{min}$. The sprinkler system had more limited effects on rectal temperature that, however, in the treatment group was significantly lower than in the control group $\left(38.7^{\circ} \mathrm{C}\right.$ to $38.8^{\circ} \mathrm{C} v s$ $39.1^{\circ} \mathrm{C}$ to $39.4^{\circ} \mathrm{C}$ ) in all the three periods of the experiment. These results show that the sprinkler system could be useful to mitigate heat stress in dairy cows.

\section{Introduction}

Cow welfare is negatively affected by heat stress induced by adverse climate conditions, which cause declines in feed intake, milk production, and fertility as well as behaviour modification (Armstrong, 1994; Bouraoui et al., 2002; Kadzere et al., 2002; West, 2003).

Heat stress can be evaluated either by measuring some physiological parameters (i.e., body temperature or respiratory rate) or by using indexes calculated from microclimatic conditions. Among the latter, the most used is the thermal humidity index (THI) (Thom, 1959). In literature, THI values were classified into categories indicating the level of heat stress experienced by animals. The definition of these levels varies among different authors. Based on what reported in Thom (1959) the following categories of Livestock Weather Safety Index were associated with THI values (Hahn et al., 2009): $\leq 74$ normal, $75 \div 78$ alert, $79 \div 83$ danger, $\geq 84$ emergency. Armstrong (1994) identified $\mathrm{THI}<72$ as no stress values, $72 \leq \mathrm{THI} \leq 78$ as indicative of mild stress, $79 \leq \mathrm{THI} \leq 89$ as limits of the moderate stress zone, and $\mathrm{THI}>90$ as cause of severe stress conditions.

For mitigating cow heat stress, different kinds of cooling systems are used and among them, sprinklers for the direct wetting of the animal body coupled with forced ventilation have positive influence on both cow physiology (e.g., reduction in rectal temperature, respiration rate, dry matter intake), behaviour (e.g., 
rumination time, lying time) and lactation performance (milk quality and yield) (Avendaño-Reyes et al., 2010; Berman, 2008, 2010; Porto et al., 2017). The direct wetting of the animal and the contemporary evaporation of the water due to intense forced ventilation induce the dissipation of a huge quantity of latent heat with relief for the animal.

In literature, the benefits induced by sprinklers systems were investigated by several research studies through experiments carried out in geographical area often characterised by hot dry climate (Chen et al., 2013, 2015, 2016; Avendaño-Reyes et al., 2012; Correa-Calderon et al., 2004). In these studies, the cooling system was proven to be effective in reducing cow heat stress. Analogous studies in zones characterised by hot-humid climate, such as those of the Mediterranean basin, are rather less frequent (Honig et al., 2012; Calegari et al., 2012) and the real benefits of this type of cooling system on cow welfare should be object of further researches, because their efficacy could be negatively affected by high levels of relative humidity. Honig et al. (2012) found that increasing the cooling frequency of high-yielding dairy cows from 5 to 8 sessions a day, improves their performances and welfare. Calegari et al. (2012) found that also with the presence of the sprinkler systems installed above the feeding alley, cows suffered a mild-moderate heat stress which was more emphasised in the pen equipped with straw bedded stalls.

The functional area where cooling is carried out could influence cow heat stress relief. In some research studies, the herd was cooled in the holding pen before the milking time (AvendañoReyes et al., 2010, 2012; Honig et al., 2012). In these cases, cows returned to their pen, or went in the milking area, after the cooling treatments. Therefore, the cooling systems did not affect the microclimate of the feeding alley and resting area, where animals spend most hours during the day. In another study (Legrand et al., 2011) animals were housed with voluntary access to a cow shower kept in the outdoor area. In other cases, the cooling was carried out in the feeding alley and in the resting area, if this last is bedded with sand. In this situation, the type of loose housing system could influence the mitigation of heat stress achievable by cooling systems. In fact, if animals have free access to a paddock (Frazzi et al., 2000; Calegari et al., 2012), heat stress due to high levels of relative humidity could be reduced by leaving the barn when microclimate becomes uncomfortable.

On this basis, the research described in this paper aimed at investigating if cow heat stress induced by hot humid climate could be mitigated by using a sprinkler system coupled with forced ventilation installed in the feeding lane in a free-stall barn equipped with a fogging system associated with forced ventilation installed in the resting area and without paddock.

\section{Materials and methods}

\section{The barn under study}

The experiment was carried out inside a free-stall dairy house (Figure 1) located in Pettineo/Pozzilli (3701' $\mathrm{N}, 14^{\circ} 32^{\prime}$ E) in the

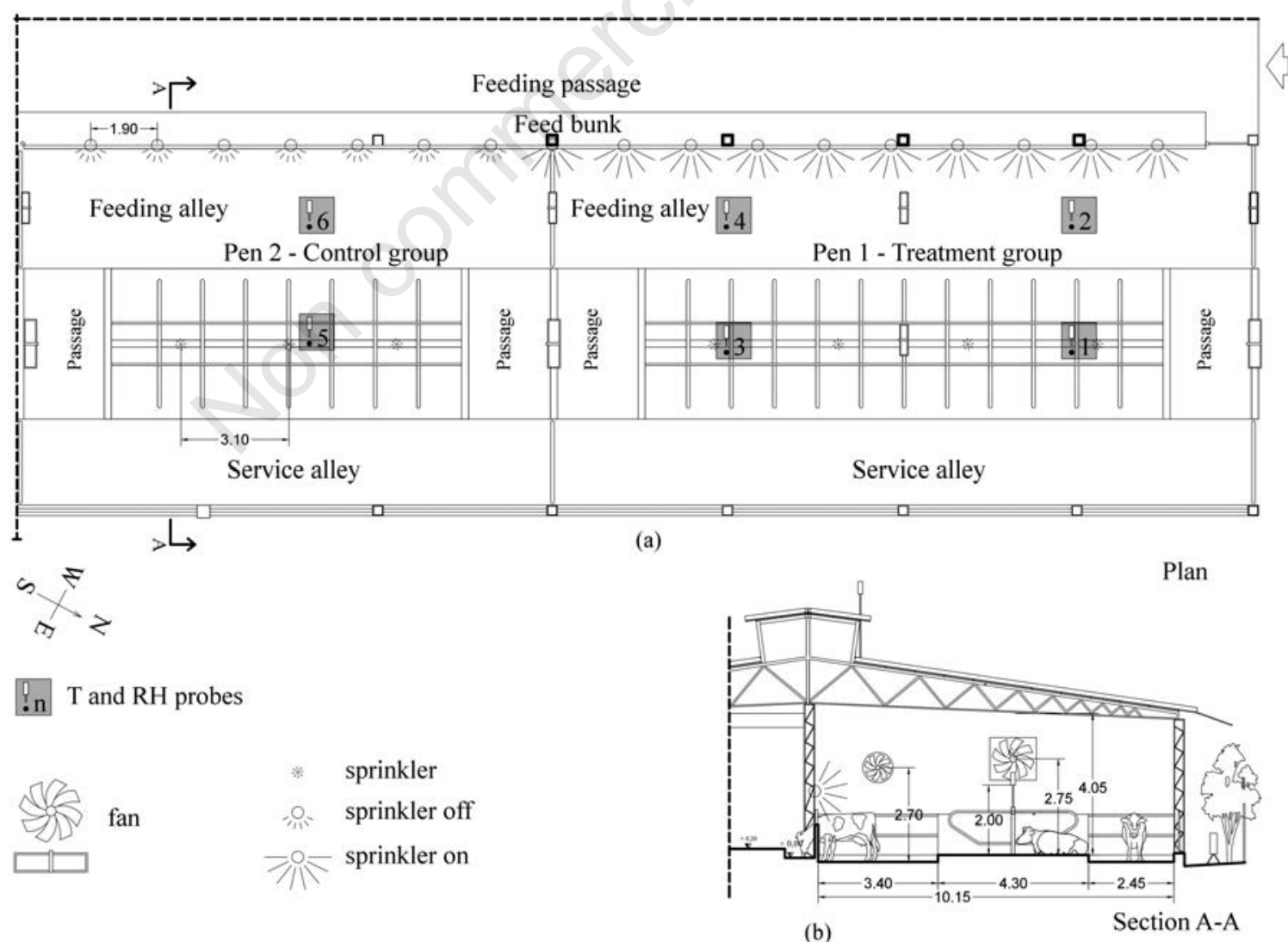

Figure 1. Plan (A) and cross section (B) of the pens where the experiment was carried out. 
province of Ragusa (Sicily, Italy), at the altitude of $234 \mathrm{~m}$ above the sea level. The sides of the barn facing SE, NE and NW were completely open (without continuous walls), whereas the side facing SW was completely closed by a continuous wall. The resting area housed 64 cubicles, bedded with sand and arranged in two rows head to head. The barn was sub-divided into 3 pens by 6 transverse passages linking service and feeding alley.

The free-stall barn was equipped with two different cooling systems (Figure 1). A fogging system associated with forced ventilation was installed in the resting area and a sprinkler system associated with forced ventilation was installed in the feeding alley.

The technical specification and the activation rules of the two systems in relation to both time and air temperature are reported in Table 1 . The fans were automatically switched off during wetting to avoid the scattering of water. Both the systems were manually switched off during the two milking sessions and the cleaning of the feeding alley.

\section{The experimental protocol}

The experiment regarded two adjacent pens of the barn: one with a resting area consisting of 26 cubicles housing 19 Italian Friesian cows (pen 1) and the other one with a resting area consisting of 16 cubicles housing 15 Italian Friesian cows (pen 2).

The experiment was structured into three different trials carried out in the following periods: $27^{\text {th }}$ June $-7^{\text {th }}$ July (P1), $25^{\text {th }}$ July - $4^{\text {th }}$ August (P2), 24 $4^{\text {th }}$ August $-3^{\text {rd }}$ September (P3). The experimental protocol of each trial required that in pen 1 the two cooling systems were always activated following an established timetable (treatment group), whereas in pen 2 the sprinkler system associated with forced ventilation was always deactivated (control group).

Rectal temperature and respiration rate of 6 cows in pen 1, and 5 cows in pen 2 were monitored at about 14:30 of each day during the three periods considered (P1, P2 and P3). During the measurements, each cow was blocked in the feeding rack. The respiration rate was measured by counting the breaths per minute with the aid of a digital timer, the rectal temperature was recorded using a digital thermometer.

Cows were fed ad libitum and feed was delivered at 8:00. The feeding area was cleaned once a day between 8:30-9:30 using a scraper driven by tractor. Cow milking occurred twice daily between 5:00-6:00 and 17:30-18:30.

\section{Data acquisition and analyses of climatic data}

Climatic parameters were measured outside and inside the barn. Air temperature and humidity were measured outdoor at the ridgeline of the roof. Air temperature and relative humidity required for the computation of THI index were measured inside the barn by positioning electronics probes in the resting area at the height of $2.00 \mathrm{~m}$ above the floor. Specifically (Figure 1), 4 probes were installed in pen 1: two above the cubicles (probes n. 1 and 3) and two above the feeding alley (probes n. 2 and 4). Furthermore, 2 probes were installed in pen 2: one above the cubicles (probe $n$. 5) and the other above the feeding alley (probe n. 6). All the sensors were connected to a data-logger that read the measurements every $5 \mathrm{~s}$ and recorded the corresponding average values every 5 min. The THI index was calculated by the following (Yousef, 1985):

$\mathrm{THI}=\mathrm{T}_{\mathrm{db}}+0.36 \mathrm{~T}_{\mathrm{dp}}+41.2$

where $\mathrm{T}_{\mathrm{db}}\left[{ }^{\circ} \mathrm{C}\right]$ is the dry-bulb temperature and $\mathrm{T}_{\mathrm{dp}}\left[{ }^{\circ} \mathrm{C}\right]$ is the dewpoint temperature calculated using the Magnus-Tetens equation (Heldman, 2003).

\section{Statistical analysis}

Means of air temperature and relative humidity measurements obtained inside the dairy house, as well as of the corresponding THI values were calculated for each probe by averaging the values of each period. One-way analysis of variance (ANOVA) was then carried out in order to test for the equality of the mean values of each probe within each period. Furthermore, for each pen, means of air temperature, relative humidity and THI values were calculated for each period by averaging the measurements acquired from all the probes. On these data, ANOVA was performed in order to test for the equality of the means among the three periods considered and, between the pens within each period.

Finally, the mean values of respiration rate and rectal temperature were calculated for each group within each period averaging the values measured on the monitored cows. Even on these data, ANOVA was performed in order to test for the equality of the means both within each period and among the three periods considered.

In the post-hoc analyses the mean values were separated by Tukey's honestly significant difference at $\mathrm{P} \leq 0.05$.

\section{Results and discussion}

Table 2 reports the statistical values of air temperature and relative humidity acquired by the probes in the three periods considered. Period P2 was characterised by the most severe climatic con-

Table 1. Timetable of the two cooling systems activation.

\begin{tabular}{|c|c|c|c|c|}
\hline & \multicolumn{2}{|c|}{ Resting area } & \multicolumn{2}{|c|}{ Feeding area } \\
\hline & Fans & Sprinklers & Fans & Sprinklers \\
\hline Technical specifications & Ventilation rate: $34,600 \mathrm{~m}^{3} / \mathrm{h}$ & $\begin{array}{c}\text { Pressure: } 200 \mathrm{kPa} \\
\text { Rate: } 1.01 \text { 1/min }\end{array}$ & Ventilation rate: $22,250 \mathrm{~m}^{3} / \mathrm{h}$ & $\begin{array}{c}\text { Pressure: } 200 \mathrm{kPa} \\
\text { Rate: } 2.57 \mathrm{l} / \mathrm{min}\end{array}$ \\
\hline Activation time & $\begin{array}{c}8: 00-9: 00 \\
10: 00-15: 00 \\
20: 30-21: 30\end{array}$ & $\begin{array}{l}11: 00-14: 30 \\
17: 00-17: 30 \\
20: 00-05: 30\end{array}$ & $\begin{array}{c}9: 00-10: 00 \\
15: 00-17: 00\end{array}$ & $\begin{array}{c}9: 00-10: 00 \\
15: 00-17: 15\end{array}$ \\
\hline Operating conditions & $\begin{array}{l}\text { Always on with } \mathrm{T}>22^{\circ} \mathrm{C} \\
\text { Operative for } 5 \text { min every } \\
25 \text { min with } \mathrm{T}<22^{\circ} \mathrm{C}\end{array}$ & $\begin{array}{c}\text { Operative for } 20 \mathrm{~s} \text { every } \\
5 \text { min with } \mathrm{T}>27^{\circ} \mathrm{C} \\
\text { Off with } \mathrm{T}<27^{\circ} \mathrm{C} \\
\end{array}$ & $\begin{array}{l}\text { Always on with } \mathrm{T}>20.9^{\circ} \mathrm{C} \\
\text { Operative for } 4 \text { min every } \\
9 \text { min with } \mathrm{T}<20.9^{\circ} \mathrm{C}\end{array}$ & $\begin{array}{c}\text { Operative for } 18 \mathrm{~s} \text { every } 13 \mathrm{~min} \\
\text { and } 38 \mathrm{~s} \text { with } \mathrm{T}>27^{\circ} \mathrm{C} \\
\text { Off with } \mathrm{T}<27^{\circ} \mathrm{C}\end{array}$ \\
\hline
\end{tabular}


ditions, with the same mean air temperature of period $\mathrm{P} 1\left(25.8^{\circ} \mathrm{C}\right)$ and a higher mean value of air relative humidity (52.4\% vs 46.8\%), whereas period P3 was characterised by a mean air temperature of about $2^{\circ} \mathrm{C}$ lower than $\mathrm{P} 1$ and $\mathrm{P} 2$, although with the highest mean value of air relative humidity $(64.9 \%)$.

The results of the ANOVA tests carried out on the values measured inside the dairy house (Table 2) show that, within each period, there was no significant difference in the mean air temperatures of all the 6 probes. This is related to the almost open layout of the building. On the contrary, air relative humidity showed an increasing gradient from the NW side to the middle of the barn. This evidence indicates that the air moisture content is poorly influenced by the presence of the sprinkler system, while it is most affected by the natural ventilation rate that is lower in the central part than along the sides of the building. Although statistically significant, the differences in air relative humidity among the probes do not exceed $9.8 \%$ in $\mathrm{P} 1,11.6 \%$ in $\mathrm{P} 2$ and $9.3 \%$ in $\mathrm{P} 3$. It is also noteworthy to point out that the maximum values of air relative humidity were recorded during nighttime, when values equal to $100 \%$ were recorded due to condensation on the probes. The differences in air relative humidity echoes in THI index values, which were higher in the middle of the barn rather than along the NW side. However, also in this case, the differences among the mean values within each period are small, ranging from 72.3 of probe $n$. 2 in $\mathrm{P} 3$ to 75.0 of probe $\mathrm{n} .5$ in P2. A similar result was found by Perissinotto et al. (2006) that, when investigated thermal preference of dairy cows housed in an environmentally controlled free-stall barn, did not significantly differences among THI values of different treatments because the building was open-sided.

As the cows were free to move within each pen, they were subjected to microclimatic conditions that are better represented by the average of the values of each probe. Therefore, in Table 3 the calculated average values are reported for probes n. 1, 2, 3 and 4, placed inside the pen 1, and n. 5 and 6 placed inside the pen 2. As expected, no significant difference was obtained between the mean air temperature of the two groups within each period, whereas the mean values of air relative humidity and, consequently, the corresponding values of THI, were significantly different. Specifically, the highest THI mean values occurred in pen 2 during all the three periods and they ranged from 73.3 in P1 to 74.7 in P2.

As regards the comparison among the mean values of each period, the results show that, in both groups, air temperature in P3 was significantly lower than in $\mathrm{P} 1$ and $\mathrm{P} 2$, and that air relative humidity increased significantly during the experiment from P1 to

Table 2. Statistical values of the climatic parameters and of the THI index in the three periods (P1, P2, P3), outside and inside the barn under study.

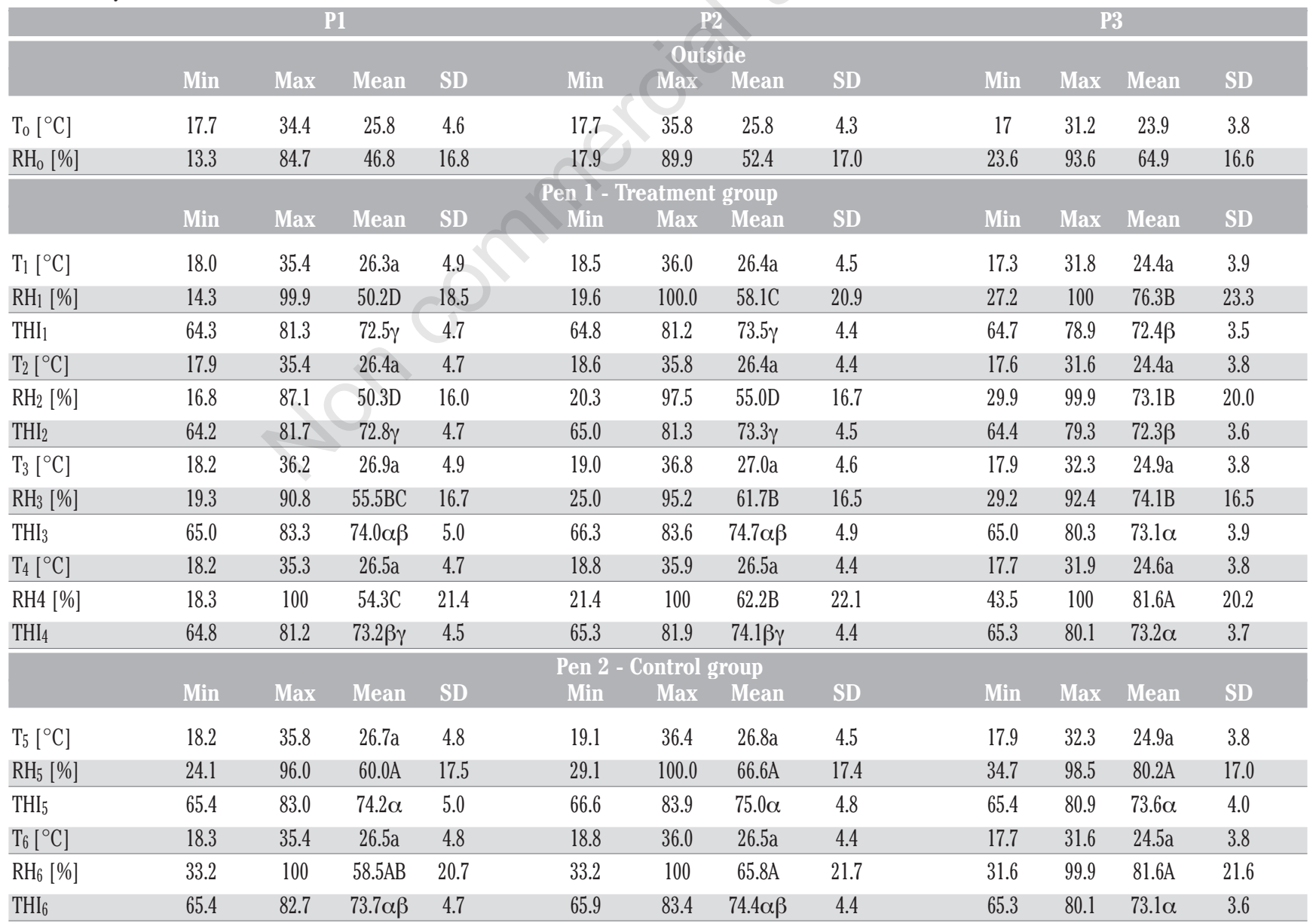

Statistical comparison was performed among the values of all the six probes. Air temperature data followed by the same lower case letters within a column are not significantly different according to the Tukey test at $\mathrm{P} \leq 0.05$; Air relative humidity data followed by the same capital letters within a column are not significantly different according to the Tukey test at $\mathrm{P} \leq 0.05 ; \mathrm{THI}$ data followed by the same Greek letters within a column are not significantly different according to the Tukey test at $\mathrm{P} \leq 0.05 . \mathrm{SD}$, standard deviation; $\mathrm{T}_{0}$, outside air temperature; $\mathrm{RH}_{0}$, outside relative humidity; $\mathrm{T}_{\mathrm{i}}$, inside air temperature measured by the probe $\mathrm{i}$; $\mathrm{RH}_{\mathrm{i}}$, inside air relative humidity measured by the probe $\mathrm{i}$; $\mathrm{THI}$, thermal humidity index calculated with the value measured by the probe $\mathrm{i}$. 
$\mathrm{P} 3$. Consequently, THI index value in $\mathrm{P} 2$ was higher than in $\mathrm{P} 1$ and P3 which, in turn, did not differ due to the counterbalanced contribution offered by air temperature and relative humidity.

A further analysis was carried out to investigate on the heat stress conditions in a short period (13:00-16:00) around the measurement of physiological parameters. The results (Table 3 ) show that, in this time interval characterised by high temperature and low relative humidity, the highest THI mean value occurred again in $\mathrm{P} 2$, but the corresponding value obtained in P1 was significantly higher than the one resultant in P3.

Summarising the previous results, during the three trials the cows of both groups were subjected to mean climatic conditions corresponding to mild or moderate heat stress. However, during daytime, air temperature and relative humidity reached values corresponding to a dangerous level of heat stress, as it is shown by the maximum THI values that were higher than or very close to 80 .

Table 4 reports the mean values of the physiological parameters measured in the monitored cows of the two groups during the three periods. All the values of the treatment group were significantly different from those ones of the control group. In the treatment group the mean value of the respiration rate was very close to the highest value of the ideal range (26-50; Merck Veterinary Manual, 2012, available from: http://www.merckvetmanual. com/appendixes/reference-guides/resting-respiratory-rates) during both P2 (51.6) and P3 (49.4), whereas it reached the maximum value of 56.4 in P1. On the contrary, in the control group, the mean values of the respiration rate were considerably higher than the ideal range during all the three periods of the experiment, as it ranged from 64.5 to 70.1 . Similar values of the respiration rate obtained in the treatment group were reported by Calegari et al. (2012), in an experiment carried out in a free-stall barn equipped with two different cooling systems and stalls bedded with different materials, i.e., sand and straw. Respiration rate, as response to a mild-moderate heat stress of the group of animals bred in the sand bedded stalls, resulted very close to that obtained in our study inside the treatment group and indicated a more favourable condition for heat dissipation in the pen with the sprinkler system.

As regards rectal temperature, in the treatment group, despite the heat stress conditions, rectal temperature values were always within the ideal range $\left(38-39.3^{\circ} \mathrm{C}\right.$; Merck Veterinary Manual, 2012, available from: http://www.merckvetmanual.com/appendixes/reference-guides/normal-rectal-temperature-ranges; Perano et al., 2015), without significant differences among the three periods. The same result was obtained by Calegari et al. (2012), for the group of cows bred in sand bedded stalls.

In the control group, rectal temperature was always significantly higher than in the treatment group. However, only in P1 it was higher than the upper limit of the ideal range $\left(39.4\right.$ vs $\left.39.3^{\circ} \mathrm{C}\right)$ indicating mild heat stress and difficulty to maintain thermoregulation. In both groups, the highest mean values of respiration rate and rectal temperature occurred in period $\mathrm{P} 1$. However, the differences between $\mathrm{P} 1$ and $\mathrm{P} 2$ were statistically significant $(\mathrm{P}<0.001)$ only for the mean values of respiration rate in the treatment group. This evidence, which is not in perfect agreement with the results of THI values, can be explained considering that in P1 the cows were subjected to a fast change of climatic conditions, which determined a remarkable rise of air temperature compared to the days immediately preceding the start of the trial. Indeed, mean air temperature during the week before the trail was $23.1^{\circ} \mathrm{C}$ that is almost $3^{\circ} \mathrm{C}$ less than the one measured in P1. Differently, in P2 the cows have had more time to adapt to a condition of thermal stress.

Rectal temperature values that are almost always inside the ideal range could be related to the mitigating effect of the cooling system installed in the cubicles area. Similar results were obtained by other Authors in analogous climate conditions when cows were cooled by evaporative cooling systems installed in the resting area (Khongdee et al., 2006; Calegari et al., 2012).

Similarly, to that found in other studies (Calegari et al., 2012; Honig et al., 2012), the above results show that the sprinkler system installed in the feeding lane allowed the effects of heat stress on dairy cows to be mitigated also in hot wet climate. Specifically, the system especially influenced the respiration rate that, in the treatment group, kept itself inside or very close to the ideal values, while in the control group it was up to 20 breath/min higher than the maximum suggested value. The sprinkler system had more limited effects on rectal temperature that, however, in the treatment group was significantly lower than in the control group in all the three periods of the experiment.

Table 3. Statistical values of the climatic parameters and of the THI index averaged for each pen in the three periods (P1, P2, P3), inside the barn under study.

\begin{tabular}{|c|c|c|c|c|c|c|c|c|c|c|c|c|}
\hline & \multicolumn{4}{|c|}{ P1 } & \multicolumn{4}{|c|}{ P2 } & \multicolumn{4}{|c|}{ P3 } \\
\hline & \multicolumn{12}{|c|}{ Pen 1 - Treatment group } \\
\hline & Min & Max & Mean & SD & Min & Max & Mean & SD & Min & Max & Mean & SD \\
\hline $\mathrm{T}_{1-4}\left[{ }^{\circ} \mathrm{C}\right]$ & 18.1 & 35.6 & $26.5 \mathrm{a}^{* *}$ & 4.8 & 18.7 & 36.1 & $26.6 \mathrm{a}^{* *}$ & 4.5 & 17.6 & 31.9 & $24.6 \mathrm{a}^{*}$ & 3.8 \\
\hline $\mathrm{RH}_{1-4}[\%]$ & 17.2 & 94.5 & $52.6 \mathrm{~B}^{+}$ & 18.0 & 21.6 & 98.1 & $59.2 \mathrm{~B}^{++}$ & 18.9 & 33.9 & 97.7 & $76.3 \mathrm{~B}^{+++}$ & 19.8 \\
\hline $\mathrm{THI}_{1-4}$ & 64.9 & 81.8 & $73.1 \beta^{\circ}$ & 4.7 & 65.4 & 82.0 & $73.9 \beta^{\circ \circ}$ & 4.5 & 64.9 & 79.7 & $72.8 \beta^{\circ}$ & 3.7 \\
\hline $\mathrm{THI}_{1-4}{ }^{(13-16)}$ & \multicolumn{4}{|c|}{$78.9^{\wedge \wedge}$} & \multicolumn{4}{|c|}{$79.6^{\wedge}$} & \multicolumn{4}{|c|}{$77.4^{\wedge \wedge \wedge}$} \\
\hline \multicolumn{13}{|c|}{ Pen 2 - Control group } \\
\hline & Min & Max & Mean & SD & Min & Max & Mean & SD & Min & Max & Mean & SD \\
\hline $\mathrm{T}_{5-6}\left[{ }^{\circ} \mathrm{C}\right]$ & 18.3 & 35.6 & $26.6 a^{* *}$ & 4.8 & 19.0 & 36.2 & $26.7 a^{* *}$ & 4.5 & 17.9 & 31.9 & $24.7 a^{*}$ & 3.8 \\
\hline $\mathrm{RH}_{5-6}$ [\%] & 29.3 & 98.0 & $59.3 \mathrm{~A}^{+}$ & 19.1 & 31.2 & 100 & $66.2 \mathrm{~A}^{++}$ & 19.5 & 33.1 & 99.2 & $80.9 \mathrm{~A}^{+++}$ & 19.2 \\
\hline $\mathrm{THI}_{5-6}$ & 65.5 & 82.9 & $74.0 \alpha^{\circ}$ & 4.8 & 66.2 & 83.4 & $74.7 \alpha^{\circ \circ}$ & 4.6 & 65.4 & 80.5 & $73.3 \alpha^{\circ}$ & 3.8 \\
\hline THI5-6 $(13-16)$ & \multicolumn{4}{|c|}{$79.8^{\wedge \wedge}$} & \multicolumn{4}{|c|}{$80.5^{\wedge}$} & \multicolumn{4}{|c|}{$78.1^{\wedge \wedge \wedge}$} \\
\hline
\end{tabular}

Air temperature data followed by the same lower case letters within a column are not significantly different according to the Tukey test at $P \leq 0.05$. Air relative humidity data followed by the same capital letters within a column are not significantly different according to the Tukey test at $\mathrm{P} \leq 0.05$; THI data followed by the same Greek letters within a column are not significantly different according to the Tukey test at $\mathrm{P} \leq 0.05$; Data followed by the same symbol within a row are not significantly different according to the Tukey test at $\mathrm{P} \leq 0.05$. SD, standard deviation; $\mathrm{T}_{\mathrm{i}-\mathrm{j}}$, average values of air temperature measured by probes $\mathrm{i}$ to $\mathrm{j}$; $\mathrm{RH}_{\mathrm{i}-\mathrm{j}}$, average values of air relative humidity measured by probes i to $\mathrm{j}$; $\mathrm{THI}_{\mathrm{i}-\mathrm{j}}$, average thermal humidity index calculated with the value measured by probes $\mathrm{i}$ to $\mathrm{j}$; $\mathrm{THI}_{\mathrm{i}-\mathrm{j}}\left({ }^{(1-16)}\right.$, average thermal humidity index calculated with the value measured by probes $i$ to $j$ in the time interval 13:00-16:00. 
Table 4. Mean values of the physiological parameter measured in the monitored cows of the two groups in the three periods (P1, P2, P3).

\begin{tabular}{lccc} 
& P1 & P2 & P3 \\
\hline Respiration rate (breaths/min) & Pen 1 - Treatment group \\
Rectal temperature $\left({ }^{\circ} \mathrm{C}\right)$ & $56.4 \mathrm{~b}^{\alpha}$ & $51.6 \mathrm{~b}^{\beta}$ & $49.4 \mathrm{~b}^{\beta}$ \\
\hline & $38.8 \mathrm{~B}^{\alpha}$ & $38.7 \mathrm{~B}^{\alpha}$ & $38.7 \mathrm{~B}^{\alpha}$ \\
\hline Respiration rate (breaths/min) & Pen 2 & Control group \\
Rectal temperature $\left({ }^{\circ} \mathrm{C}\right)$ & $70.1 \mathrm{a}^{\alpha}$ & $64.5 \mathrm{a}^{\beta}$ & $66.6 \mathrm{a}^{\alpha \beta}$ \\
\hline Resp & $39.4 \mathrm{~A}^{\alpha}$ & $39.2 \mathrm{A \alpha}^{\beta}$ & $39.1 \mathrm{~A}^{\beta}$ \\
\hline
\end{tabular}

Respiration rate data followed by the same lower case letters within a column are not significantly different according to the Tukey test at $\mathrm{P} \leq 0.05$; Rectal temperature data followed by the same capital letters within a column are not significantly different according to the Tukey test at $\mathrm{P} \leq 0.05$; Data followed by the same Greek letters within a row are not significantly different according to the Tukey test at $P \leq 0.05$

\section{Conclusions}

The effects of heat stress on lactating dairy cows were investigated when a cooling system consisting of sprinklers and fans is installed in the feeding alley. The results achieved in this study could be considered an advancement of the state of knowledge with regard physiological responses of dairy cows bred in a freestall barn without access to paddock and subjected to heat stress induced by hot wet climate. Specifically, rectal temperatures and respiratory rate of a group of cows cooled by the sprinkler system were compared with the ones of a control group.

The main results could be summarised as follows. The sprinkler system did not influence the microclimatic conditions as the barn was completely open on three sides. This condition determined that the two groups of cows were exposed to the same mild or moderate heat stress, although during the day time THI reaches values higher than 80 . The sprinkler system had a moderate positive effect on the rectal temperature values, which were almost always inside the ideal value, although little increases were recorded in the control group.

However, higher respiratory rates were recorded for dairy cows of the control group compared to those of the treated group. This outcome makes it possible to suppose that the sprinkler system was able to mitigate heat stress in dairy cows.

\section{References}

Armstrong D.V. 1994. Heat stress interaction with shade and cooling. J. Dairy Sci. 77:2044-50.

Avendaño-Reyes L., Álvarez-Valenzuela F.D., Correa-Calderón A., Algándar-Sandoval A., Rodríguez-González E., PérezVelázquez R., Macías-Cruz U., Díaz-Molina R., Robinson P.H., Fadel J.C. 2010. Comparison of three cooling management systems to reduce heat stress in lactating Holstein cows during hot and dry ambient conditions. Livestock Sci. 132:48-52.

Avendaño-Reyes L., Hernández-Rivera J.A., Álvarez-Valenzuela F.D., Macías-Cruz U., Díaz-Molina R., Correa-Calderón A., Robinson P.H., Fadel J.G. 2012. Physiological and productive responses of multiparous lactating Holstein cows exposed to short-term cooling during severe summer conditions in an arid region of Mexico. Int. J. Biometeorol. 56:993-9.
Berman A. 2008. Increasing heat stress relief produced by coupled coat wetting and forced ventilation. J. Dairy Sci. 91:4571-8.

Berman A. 2010. Forced heat loss from body surface reduces heat flow to body surface. J. Dairy Sci. 93:242-8.

Bouraoui R., Lahmar M., Majdoub A., Djemali M., Belyea R. 2002. The relationship of temperature-humidity index with milk production of dairy cows in a Mediterranean climate. Animal Res. 51:479-91.

Calegari F., Calamari L., Frazzi E. 2012. Misting and fan cooling of the rest area in a dairy barn. Int. J. Biometeorol. 56:287-95.

Chen J.M., Schütz K.E., Tucker C.B. 2013. Dairy cows use and prefer feed bunks fitted with sprinklers. J. Dairy Sci. 96:5035-45.

Chen J.M., Schütz K.E., Tucker C.B. 2015. Cooling cows efficiently with sprinklers: Physiological responses to water spray. J. Dairy Sci. 98:6925-38.

Chen J.M., Schütz K.E., Tucker C.B. 2016. Cooling cows efficiently with water spray: Behavioral, physiological, and production responses to sprinklers at the feed bunk. J. Dairy Sci. 99:4607-18.

Correa-Calderon A., Armstrong D., Ray D., DeNise S., Enns M., Howison C. 2004. Thermoregulatory responses of Holstein and Brown Swiss heat-stressed dairy cows to two different cooling systems. Int. J. Biometeorol. 48:142-8.

Frazzi E., Calamari L., Calegari F., Stefanini L. 2000. Behavior dairy cows in response to different barn cooling systems. Trans. ASAE. 43:387-94.

Hahn G.L., Gaughan J.B., Mader T.L., Eigenberg R.A. 2009. Thermal indices and their applications for livestock environments. In J.A. DeShazer (Ed.), Livestock energetics and thermal environmental management. ASABE, St. Joseph, MI, USA, pp. 113-130.

Heldman D.R. 2003. Encyclopedia of agricultural, food, and biological engineering. Marcel Dekker, New York, NY, USA.

Honig H., Miron J., Lehrer H., Jackoby S., Zachut M., Zinou A., Portnick Y., Moallem U. 2012. Performance and welfare of high-yielding dairy cows subjected to 5 or 8 cooling sessions daily under hot and humid climate. J. Dairy Sci. 95:3736-42.

Kadzere C.T., Murphy M.R., Silanikove N., Maltz E. 2002. Heat stress in lactating dairy cows: a review. Livestock Prod. Sci. 77:59-91.

Khongdee S., Chaiyabutr N., Hinch G., Markvichitr K., Vajrabukka C. 2006. Effects of evaporative cooling on reproductive performance and milk production of dairy cows in hot wet conditions. Int. J. Biometeorol. 50:253-7.

Legrand A., Schütz K.E., Tucker C.B. 2011. Using water to cool cattle: behavioral and physiological changes associated with voluntary use of cow showers. J. Dairy Sci. 94:3376-86.

Perano K.M., Usack J.G., Angenent L.G., Gebremedhin K.G. 2015. Production and physiological responses of heat-stressed lactating dairy cattle to conductive cooling. J. Dairy Sci. 98:5252-61.

Perissinotto M., Moura D.J., Matarazzo S.V., Mendes A.S., Naas I.A. 2006. Behavior of dairy cows housed in environmentally controlled freestall. Agric. Eng. Int. Vol. VIII. Manuscript BC 05016. International Commission of Agricultural Engineering, Beijing, China.

Porto S.M.C., D'Emilio A., Cascone G. 2017. On the influence of the alternation of two different cooling systems on dairy cow daily activities. J. Agricult. Engine. 577:21-7.

Thom E.C. 1959. The discomfort index. Weatherwise. 12:57-60

Yousef M.K. 1985. Stress physiology in livestock. CRC Press, Boca Raton, FL, USA.

West J.W. 2003. Effects of heat-stress on production in dairy cattle. J. Dairy Sci. 86:2131-44. 